DOI: https://doi.org/10.24867/10AM01Radovic

\title{
ELEKTROLUČNO ZAVARIVANJE U AKTIVNOM ZAŠTITNOM GASU PODRŽANO ULTRAZVUČNIM VIBRACIJAMA
}

\section{ELECTRIC ARC IN SHIELDING GAS WELDING SUPPORTED BY ULTRASONIC VIBRATIONS}

\author{
Damjan Radović, Sebastian Baloš, Fakultet tehničkih nauka, Novi Sad
}

\begin{abstract}
Oblast - MAŠINSTVO
Kratak sadržaj - U ovom radu izvršeno je eksperimentalno zavarivanje MAG postupkom zavarivanja podržano ultrazvukom. Uzorci zavareni različitim parametrima su ispitani metalografski i ispitivana je mikrotvrdoća. Pokazano je da ultrazvučna obrada utiče na eliminaciju stubaste strukture, karakteristične za elektrolučne postupke zavarivanja. Pored toga, javlja se smanjenje sadržaja Vidmanštetenovog $i$ alotriomorfnog ferita, a povećanje sadržaja igličastog ferita. Kao posledica, javlja se povećanje mikrotvrdoće u metalu šava. Pored toga, smanjuje se razugljeničenje na površini, što sve ukazuje da je brzina kristalizacije uz prisustvo ultrazvuka povećana $u$ odnosu na konvencionalno MAG zavarivanje.
\end{abstract}

Ključne reči: $M A G$ zavarivanje, Ultrazvučna obrada, Mikrostruktura, Mikrotvrdoća

\begin{abstract}
In this work, experimental MAG welding supported by ultrasonic vibrations was studied. Metallographic examination and microhardness were done on the obtained specimens. It was shown that no columnar structure occurs, the typical feature of the arc welding weldments. Also, Widmanstaetten and allotriomorphic ferrite content is decreased, while acicular ferrite content increases. As a consequence, microhardness in the weld metal increases. Finally, decarburization on the surface is decreased, which all indicates an increased crystallization rate with ultrasonic vibrations applied, compared to conventional MAG welding.
\end{abstract}

Keywords: MAG welding, Ultrasonic treatment, Microstructure, Microhardness

\section{UVOD}

Zavarivanje omogućava postizanje materijalnog kontinuiteta između elemenata koji se zavaruju, pri čemu zavareni spoj treba da ima što veću sličnost osobina sa osobinama osnovnog materijala.

Spojevi nastali zavarivanjem spadaju u grupu neraskidivih spojeva čija se neraskidivost ostvaruje pomoću atomskomolekularnih sila koje vladaju između elementarnih čestica zavarenih materijala [1].

\footnotetext{
NAPOMENA:

Ovaj rad proistekao je iz master rada čiji mentor je bio dr Sebastian Baloš, vanr. prof.
}

Kod MAG (Metal Active Gas) postupka zavarivanja električni luk se uspostavlja između osnovnog materijala i žice za zavarivanje koja je ujedno i dodatni materijal. Najčešće se koristi jednosmerna struja obrnute polarnosti. Nakon uspostavljanja električnog luka sledi dodavanje žice za zavarivanje u električni luk, žica se topi i dolazi do formiranja zavarenog spoja [2]. U zavisnosti od vrste zaštitnog gasa elektrolučno zavarivanje topljivom elektrodom se skraćeno obeležava kao MAG (Metal Aktivni Gas) ili MIG (Metal Inertni Gas). Kod MAG postupka se kao zaštita koristi $\mathrm{CO} 2$ (ugljen-dioksid) ili mešavina gasova koja se ponaša kao aktivni gas, a kod MIG postupka Ar, He (argon, helijum) ili mešavina gasova koja se ponaša kao inertni gas $[3,4]$.

Jedan od aktuelnih pravaca razvoja je vibraciona obrada, koja se može primenjivati $u$ toku zavarivanja i nakon zavarivanja [5]. Vibraciona obrada $\mathrm{u}$ toku postupka zavarivanja se primenjuje sa ciljem poboljšanja mehaničkih osobina zavarenog spoja. Brojnim eksperimentima se pokušava formirati baza znanja o prednostima i nedostacima primene vibracija $\mathrm{u}$ toku zavarivanja, sa ciljem da se izbegnu greške zavarivanja [6].

\section{EKSPERIMENTALNI RAD}

Tokom eksperimentalnog istraživanja korišten je konstrukcioni čelik S275JR debljine $3 \mathrm{~mm}$, aparat za zavarivanje DynaMig 450 sa dodatni materijalom u vidu pune žice SG3 prečnika $1 \mathrm{~mm}$, zaštitni gas C18 (mešavina $82 \%$ argona i ugljen-dioksida $18 \%$ ) i ultrazvučni generator MPI2000.

Tabela 1. Hemijski sastav osnovnog materijala (\%)

\begin{tabular}{|l|l|l|l|l|l|}
\hline $\mathbf{C}$ & $\mathbf{S i}$ & $\mathbf{M n}$ & $\mathbf{S}$ & $\mathbf{C r}$ & $\mathbf{P}$ \\
\hline 0,11 & 0,16 & 0,52 & 0,039 & $<0,002$ & 0,011 \\
\hline $\mathbf{A l}$ & $\mathbf{C u}$ & $\mathbf{M o}$ & $\mathbf{N i}$ & $\mathbf{T i}$ & $\mathbf{F e}$ \\
\hline 0,006 & 0,35 & 0,012 & 0,083 & $<0,002$ & ostatak \\
\hline
\end{tabular}

$\mathrm{Na}$ radnu ploču koja prenosi vibracije su postavljena dva lima dimenzija 150x40x3mm, koja su pričvršćena pomoću vijaka. Limovi su postavljeni sučeono i koristi se I oblik žljeba dok se rastojanje između limova menjalo tokom eksperimenta. Tokom prethodnih eksperimenata došlo se do zaključka da je najpovoljniji tehnološki postupak u kojem se nakon uspostavljanja električnog luka uključuje vibracioni uređaj i pre prekidanja električnog luka se gasi vibracioni uređaj. Odnosno, uspostavljanje i prekidanje električnog luka nije pod uticajem vibracija dok se formiranje šava između ova dva procesa odvija pod uticajem vibracija. U tabeli 2 nalaze se tehnološki parametri koji su primenjeni prilikom formiranja uzoraka. 
Iz zavarenih ploča su isečeni gore navedeni uzorci za makroskopska i mikroskopska ispitivanja. Uzorci za makro i mikro ispitivanja 1, 2 i 3 su izabrani tako da prikazuju najčešće greške koje su primećene tokom eksperimenta, dok su uzorci 0 i 4 dobijeni bez grešaka.

Tabela 2. Tehnološki parametri spajanja uzoraka

\begin{tabular}{|c|c|c|c|c|c|}
\hline \multirow{4}{*}{ Uzorak 0} & \multirow[t]{2}{*}{ Ultrazvučni uređaj } & Položaj & Frekvencija [Hz] & Jačina struje $[\mathrm{A}]$ & $\begin{array}{l}\text { Snaga } \\
{[\mathrm{kW}]}\end{array}$ \\
\hline & & - & - & - & - \\
\hline & \multirow[t]{2}{*}{$\begin{array}{c}\text { Aparat za } \\
\text { zavarivanje }\end{array}$} & Napon luka [V] & Jačina struje $[\mathrm{A}]$ & $\begin{array}{c}\text { Brzina dodavanja } \\
\text { žice }[\mathrm{m} / \mathrm{min}]\end{array}$ & $\begin{array}{l}\text { Zazor } \\
{[\mathrm{mm}]}\end{array}$ \\
\hline & & 18 & 120 & 4,5 & 1,5 \\
\hline \multirow{4}{*}{ Uzorak 1} & \multirow[t]{2}{*}{ Ultrazvučni uređaj } & Položaj & Frekwencija [Hz] & Jačina struje $[\mathrm{A}]$ & $\begin{array}{l}\text { Snaga } \\
{[\mathrm{kW}]}\end{array}$ \\
\hline & & vertikalni & 20060 & 2.2 & 1,2 \\
\hline & \multirow[t]{2}{*}{$\begin{array}{c}\text { Aparat za } \\
\text { zavarivanje }\end{array}$} & Napon luka [V] & Jačina struje $[\mathrm{A}]$ & $\begin{array}{c}\text { Brzina dodavanja } \\
\text { žice }[\mathrm{m} / \mathrm{min}]\end{array}$ & $\begin{array}{l}\text { Zazor } \\
{[\mathrm{mm}]}\end{array}$ \\
\hline & & 18 & 120 & 4,5 & 1,5 \\
\hline \multirow{4}{*}{ Uzorak 2} & \multirow[t]{2}{*}{ Ultrazvučni uređaj } & Položaj & Frekvencija [Hz] & Jačina struje $[\mathrm{A}]$ & $\begin{array}{l}\text { Snaga } \\
{[\mathrm{kW}]}\end{array}$ \\
\hline & & vetrikalni & 20060 & 2,2 & 1,2 \\
\hline & \multirow[t]{2}{*}{$\begin{array}{c}\text { Aparat za } \\
\text { zavarivanje }\end{array}$} & Napon luka [V] & Jačina struje[A] & $\begin{array}{c}\text { Brzina dodavanja } \\
\text { žice }[\mathrm{m} / \mathrm{min}]\end{array}$ & $\begin{array}{l}\text { Zazor } \\
{[\mathrm{mm}]}\end{array}$ \\
\hline & & 17,5 & 100 & 4,5 & 1,5 \\
\hline \multirow{4}{*}{ Uzorak 3} & \multirow[t]{2}{*}{ Ultrazvučni uređaj } & Položaj & Frekvencija $[\mathrm{Hz}]$ & Jačina struje $[\mathrm{A}]$ & $\begin{array}{l}\text { Snaga } \\
{[\mathrm{kW}]}\end{array}$ \\
\hline & & Vertikalni & 20060 & 2,2 & 1,2 \\
\hline & \multirow[t]{2}{*}{$\begin{array}{c}\text { Aparat za } \\
\text { zavarivanje }\end{array}$} & Napon luka [V] & Jačina struje $[\mathrm{A}]$ & $\begin{array}{c}\text { Brzina dodavanja } \\
\text { žice }[\mathrm{m} / \mathrm{min}]\end{array}$ & $\begin{array}{l}\text { Zazor } \\
{[\mathrm{mm}]}\end{array}$ \\
\hline & & 17,5 & 100 & 4,5 & 1,2 \\
\hline \multirow{4}{*}{ Uzorak 4} & \multirow[t]{2}{*}{ Ultrazvučni uređaj } & Položaj & Frekvencija [Hz] & Jačina struje $[\mathrm{A}]$ & $\begin{array}{l}\text { Snaga } \\
{[\mathrm{kW}]}\end{array}$ \\
\hline & & horizontalni & 20082 & 0,8 & 0,5 \\
\hline & \multirow[t]{2}{*}{$\begin{array}{c}\text { Aparat za } \\
\text { zavarivanje }\end{array}$} & Napon luka [V] & Jačma struje [A] & $\begin{array}{c}\text { Brzina dodavanja } \\
\text { žice }[\mathrm{m} / \mathrm{min}]\end{array}$ & $\begin{array}{l}\text { Zazor } \\
{[\mathrm{mm}]}\end{array}$ \\
\hline & & 18 & 120 & 4,5 & 1,2 \\
\hline
\end{tabular}

Ispitivanje mikrostrukture izvršeno je na svetlosnom mikroskopu Leitz Orthoplan, a analizirane su mikrostruktura osnovnog materijala, ZUT-a i mikrostruktura metala šava.

Izvršena je standardna priprema uzoraka za metalografska ispitivanja na opremi Struers: isecanje, zatapanje uzoraka u autopolimerizirajući akrilat, brušenje vodobrusnim papirima granulacije P150-P2500, poliranje uzoraka tkaninama za poliranje dijamantskim suspenzijama $6 \mu \mathrm{m}$,
$3 \mu \mathrm{m}$ i $1 \mu \mathrm{m}$ i nagrizanje Nitalom $\left(3 \% \mathrm{HNO}_{3}\right.$ i $97 \%$ etanol).

Ispitivanje mikrotvrdoće izvršeno je na poprečnom preseku zavarenog spoja po Vikersu pri opterećenju od $0.2 \mathrm{~kg}$ na uzorcima $\mathrm{za}$ analizu mikrostrukture po završetku mikrostrukturne analize, prema šemi 1, sa rastojanjem između otisaka od $0,15 \mathrm{~mm}$.

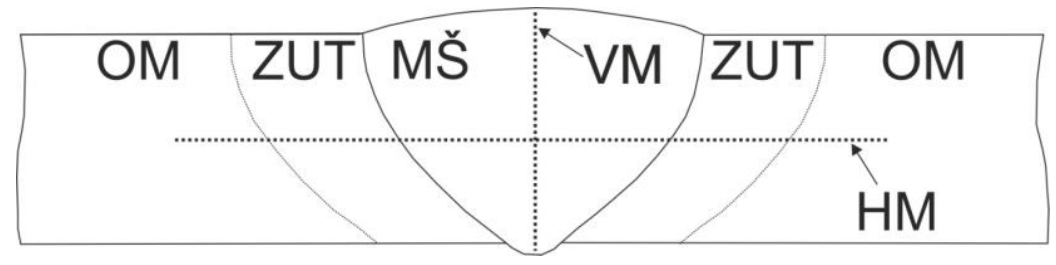

Slika 1. Merenje tvrdoće u horizontalnom pravcu (HM) i vertikalnom pravcu (VM)

\section{REZULTATI I DISKUSIJA}

Makro prikaz zavarenih spojeva dat je na slikama 2-6. Na slici 2 je prikazan nulti uzorak na kojem se primećuju stubasti kristali, koji su rasli od graničnih kristala osnovnog materijala i sučeljavaju se na sredini spoja tj. primetna je usmerena stubičasta struktura. Ovaj uzorak nije nastao pod uticajem ultrazvučne obrade tako da se koristi kao referntni uzorak. Na makroskopskim prikazima uzoraka 1, 2 i 3 su vidljive prsline i nepravilnosti oblika šava. Na slici 6, gde je prikazan uzorak 4, se ne primećuju predhodno navedene greške. U odnosu na nulti uzorak uzorci zavareni pod uticajem ultrazvučne obrade nemaju izraženu stubastu mikrostrukturu. 


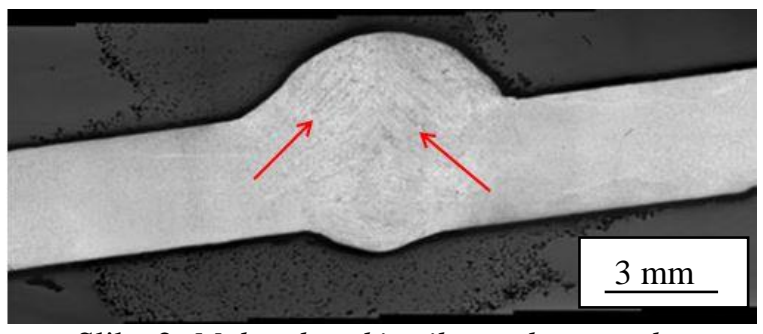

Slika 2. Makroskopski prikaz nultog uzorka

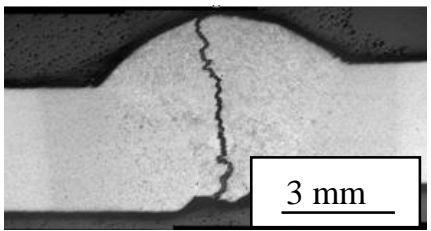

Slika 3. Makroskopski prikaz prvog uzorka

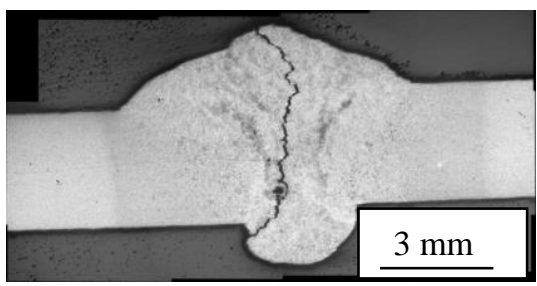

Slika 4. Makroskopski prikaz drugog uzorka

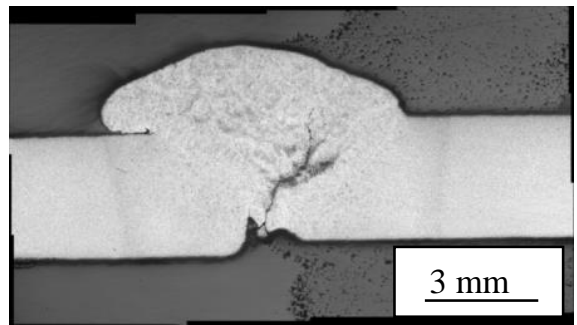

Slika 5. Makroskopski prikaz trećeg uzorka

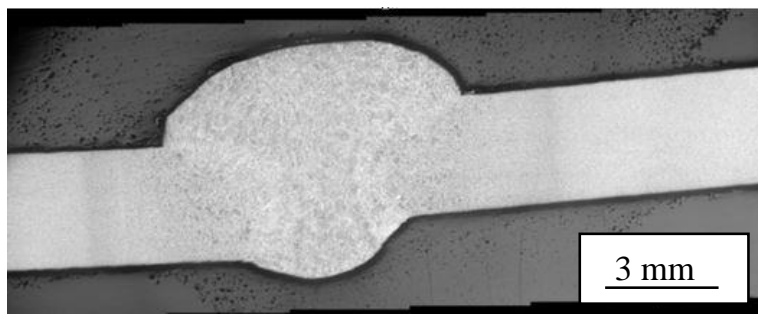

Slika 6. Makroskopski prikaz četvrtog uzorka

Na slikama 7 i 8 prikazana je mikrostruktura središnjeg dela metala šava nultog i četvrtog uzorka. Na nultom uzorku koji je prikazan na slici 10 primetan je igličasti ferit, Vidmanštetenov ferit i alotriomorfni ferit. $\mathrm{Na}$ ovoj slici se takođe primećuje stubičasta struktura kristala. $\mathrm{Na}$ uzorcima nastalim pod uticajem ultrazvučne obrade prisutan je acikularni igličasti ferit i znatno manje količine alotriomorfnog i Vidmanštetenovog ferita. Takođe na ovim uzorcima se ne primećuje usmerenost kristala kao na nultom uzorku.
Rezultati mikrotvrdoće su prikazani na dijagramima prikazanim na slikama 9 i 10 . Vidi se da su vrednosti mikrotvrdoće veći kod uzorka 4 u odnosu na uzorak 0 .

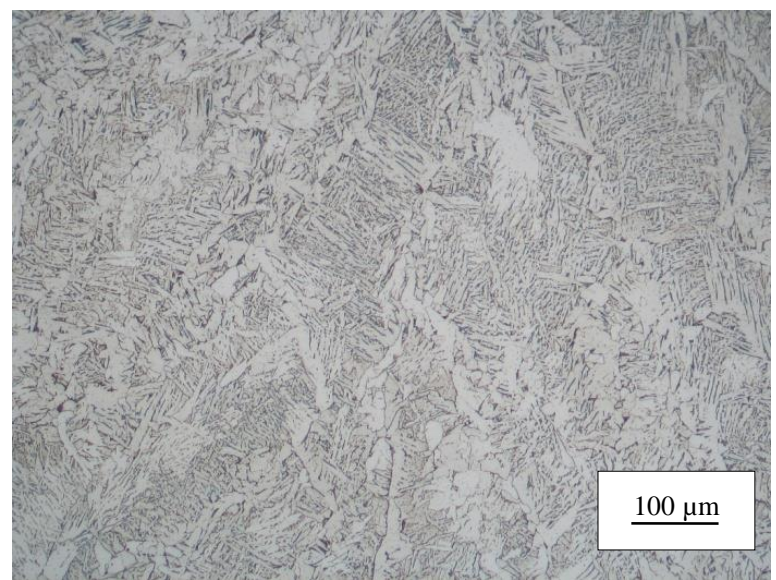

Slika 7. Mikrostruktura središnjeg dela metala šava nultog uzorka

Povećanje mikrovrdoće je direktno povezano sa promenom mikrostrukture. Naime, povećanje sadržaja igličastog ferita na račun smanjenja Vidmanštetenovog i alotriomorfnog ferita kod uzorka 0 ima značajan uticaj na povećanje mikrotvrdoće, s obzirom na znatno manju veličinu zrna kod igličastog ferita. Pored toga, može se konstatovati da je dejstvo ultrazvuka povezano i sa eliminacijom usmerenosti kristala, verovatno $\mathrm{kroz}$ mehanizam povećanja broja centara kristalizacije, što je u skladu sa [7].

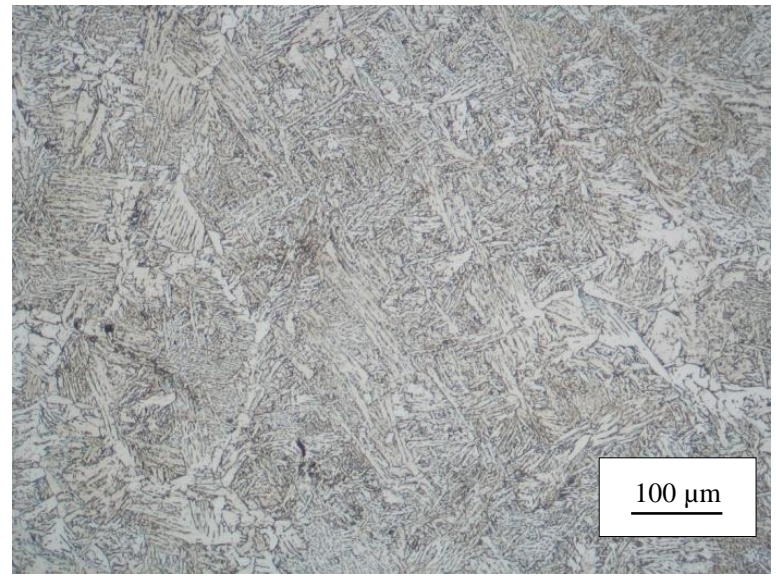

Slika 8. Mikrostruktura središnjeg dela metala šava četvrtog uzorka

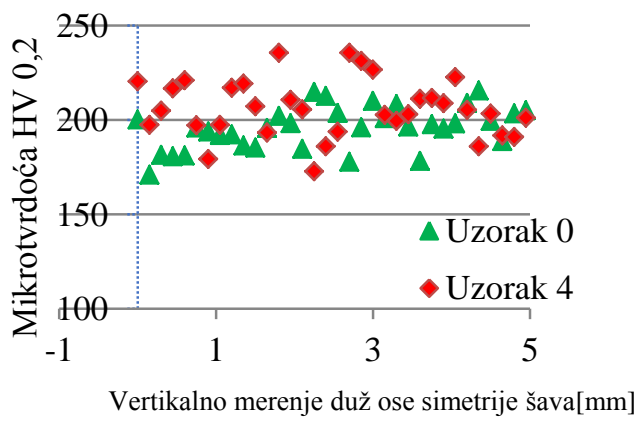

Slika 9. Poređenje vertikalnog merenja mikrotvrdoće uzorka 0 i uzorka 4 


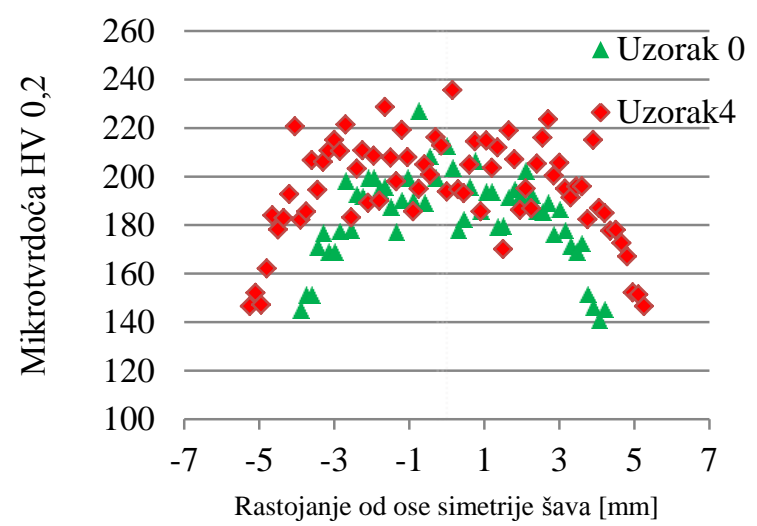

Slika 10. Poređenje horizontalnog merenja mikrotvrdoće uzorka 0 i uzorka 4

\section{ZAKLJUČAK}

$\mathrm{Na}$ osnovu provodenog eksperimenta mogu se izvući određeni zaključci.

- Najveći uticaj na kvalitet zavara ima snaga ultrazvučnih vibracija i položaj sonotrode u odnosu na predmet obrade.

- Usled dejstva ultrazvuka, stubasta struktura se ne pojavljuje, smanjuje se sadržaj Vidmanštetenovog i alotriomorfnog ferita, a povećava se sadržaj igličastov ferita

- Tvrdoća metala šava se povećava usled dejstva ultrazvuka tokom MAG zavarivanja, što je posledica šovećanog sadržaja igličastog ferita u metalu šava. Povećana tvrdoća je indikator veće čvrstoće metala šava.

Na osnovu prethodnog, može da se generalno zaključi da je ultrazučni tretman tokom MAG zavarivanja koristan sa gledišta povećanja mehaničkih osobina, kako MAG, tako verovatno i MIG i TIG zavarivanja, sa mogućnošću upotrebe i na druge materijale, kao što su nerđajući čelici i legure obojenih metala, kao što su legure aluminijuma.

\section{LITERATURA}

[1] A. Blagojević, O. Pašić, "Zavarivanje lemljenje lijepljenje”, Mostar, Mašinski Fakultet Mostar, Mašinski Fakultet Banjaluka, 1991.

[2] N. Atlija, "MAG postupak zavarivanj", Rijaka, Sveučilište u Rijeci, 2016.

[3] M. Klobučar, "Teorijske i praktične osnove MIG/MAG postupka zavarivana”, Varaždin, Sveučilište Sjever Varaždin, 2016.

[4]D. Seferijan, (preveo: R. Arsenijević), "Metalurgija Zavarivanja“, Građevinska knjiga Beograd. Beograd. 1969.

[5] B. Sabo, "Prilog istraživanju uticaja vibracione obrade na zaostale deformacije $i$ napone zavarenih nosača", Novi Sad, Fakultet tehničkih nauka u Novom Sadu, 1997.

[6] M.J.Jose, S.S.Kumar, A.Sharma, "Vibration assisted welding processes and their influence on quality of welds"،, Science and technology of welding Joining. Volume 21. 2016. pages: 243-258

[7]S. Kumar, C.S. Wu, G.K. Padhy, W. Ding, "Application of ultrasonic vibrations in welding and metal processing", Journal of Manufacturing Processes. Volume 26. 2017. pages: 295-322

\section{Kratka biografija:}

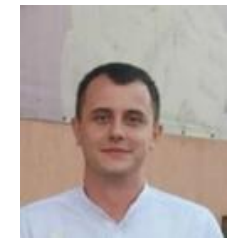

Damjan Radović rođen je u Trebinju 1994. god. Diplomski rad na Fakultetu tehničkih nauka iz oblasti Mašinstvo Matreijali i tehnologije spajanja odbranilo je 2017. god. Kontakt: damjan.radovic.994@gmail.com

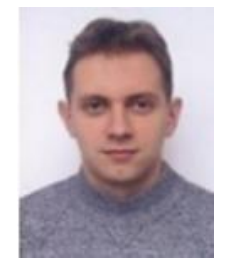

Sebastian Baloš rođen je u Somboru 1974. god. Doktorirao je na Fakultetu tehničkih nauka 2010. godine, a 2011. godine je biran u zvanje docenta. Od 2016. godine, u zvanju je vanrednog profesora u užoj naučnoj oblasti Materijali i tehnologije spajanja. 